\title{
Everolimus for treatment-refractory seizures in TSC
}

\author{
Extension of a randomized controlled trial
}

\begin{abstract}
David N. Franz, MD, John A. Lawson, MD, Zuhal Yapici, MD, Hiroko Ikeda, MD, Tilman Polster, MD, Rima Nabbout, MD, Paolo Curatolo, MD, Petrus J. de Vries, PhD, Dennis J. Dlugos, MD, Maurizio Voi, MD, Jenna Fan, MD, Alexandra Vaury, MSc, Diana Pelov, MS, and Jacqueline A. French, MD
\end{abstract}

Correspondence

Dr. Franz

david.franz@cchmc.org

Neurology: Clinical Practice October 2018 vol. 8 no. 5 412-420 doi:10.1212/CPJ.0000000000000514

\begin{abstract}
\section{Background}

EXamining everolimus In a Study of Tuberous sclerosis 3 (EXIST-3) demonstrated significantly reduced seizure frequency (SF) with everolimus vs placebo. In this study, we evaluate the long-term efficacy and safety of everolimus for tuberous sclerosis complex (TSC)-associated treatment-refractory seizures.

\section{Methods}

After completion of the core phase, patients could enter an open-label extension phase and receive everolimus (target exposure, $3-15 \mathrm{ng} / \mathrm{mL}$ ) for $\geq 48$ weeks. Efficacy end points included change from baseline in average weekly SF expressed as response rate ( $\mathrm{RR}, \geq 50 \%$ reduction) and median percentage reduction (PR).
\end{abstract}

\section{Results}

Of 366 patients, 361 received everolimus in core/extension phases. The RR was $31 \%(95 \% \mathrm{CI}, 26.2-36.1 ; \mathrm{N}=352)$ at week $18,46.6 \%(95 \% \mathrm{CI}$, $40.9-52.5 ; \mathrm{N}=298)$ at 1 year, and $57.7 \%(95 \% \mathrm{CI}, 49.7-65.4 ; \mathrm{N}=163)$ at 2 years. Median PR in SF was 31.7\% (95\% CI, 28.5-36.1) at week 18, 46.7\% (95\% CI, 40.2-54) at 1 year, and 56.9\% (95\% CI, 50-68.4) at 2 years. Ninety-five patients (26.3\%) discontinued everolimus before 2 years; 103 (28.5\%) had <2 years of follow-up at study cutoff, and $40 \%$ were exposed to everolimus for $\geq 2$ years. An analysis classifying discontinued patients as nonresponders showed an RR of $30.2 \%(95 \% \mathrm{CI}, 25.5-35.2 ; \mathrm{N}=361)$ at week 18, 38.8\% (95\% CI, 33.7-44.1; $\mathrm{N}=358$ ) at 1 year, and $41 \%(95 \% \mathrm{CI}, 34.6-47.7 ; \mathrm{N}=229)$ at 2 years, suggesting sustained benefit over time. The incidence of grade $3 / 4$ adverse events (AEs) (any cause) was $40.2 \%$, and $13 \%$ discontinued because of AEs (pneumonia [1.7\%] and stomatitis [1.4\%]). Two deaths were suspected to be treatment-related (pneumonia and septic shock).

\section{Conclusions}

Sustained reductions in TSC-associated treatment-refractory seizures over time were achieved with adjunctive everolimus. The safety profile was consistent with the core phase with no new safety concerns.

\section{Classification of evidence}

This study provides Class IV evidence that long-term everolimus therapy reduces SF in patients with TSCassociated treatment-refractory seizures.

\section{MORE ONLINE}

$\rightarrow$ Class of Evidence

Criteria for rating therapeutic and diagnostic studies

NPub.org/coe 
Epilepsy affects as many as $80 \%-90 \%$ of patients with tuberous sclerosis complex (TSC). ${ }^{1,2}$ Approximately, $60 \%$ of these become refractory to conventional antiepileptic drugs (AEDs), ${ }^{3}$ which highlights the need for development of more effective treatments. Dysregulation and overactivation of the mammalian target of rapamycin (mTOR) pathway due to mutations in either the TSC1 or TSC2 genes are causally linked to the cortical malformations, intellectual disability, and epilepsy in TSC. ${ }^{4}$ Preclinical and preliminary clinical studies have demonstrated seizure reduction and potential disease-modifying effects of mTOR inhibitors in patients with TSC experiencing epilepsy. ${ }^{1,5-8}$ Everolimus, an oral mTOR inhibitor, was investigated as an adjunctive therapy for the treatment of refractory seizures associated with TSC in the EXIST-3 trial. ${ }^{9}$ The 2 trough exposure ranges of everolimus used in the study (3-7 ng/mL [low exposure (LE)] and 9-15 ng/mL [high exposure $(\mathrm{HE})]$ ) were superior to placebo for the coprimary end points of $50 \%$ response rate $(R R, 28.2 \%$ and $40 \%$ vs $15.1 \%$ ) and median percentage reduction (PR) in seizure frequency (SF, $29.3 \%$ and $39.6 \%$ vs $14.9 \%$ ), during the 12 -week maintenance period of the core phase. ${ }^{9}$ There has been a growing interest in understanding what happens when patients with TSC are maintained on everolimus in the longer term for the following reasons. The first is a concern regarding whether there are additional risks when maintaining treatment over a longer duration. The second is whether seizure improvement persists or potentially increases over time since everolimus addresses the underlying pathophysiology of epileptogenicity in TSC, rather than only suppressing seizures. In this study, we report the long-term efficacy and safety of everolimus from the EXIST-3 study when all patients have completed $\geq 48$ weeks of the extension phase of the study.

\section{Methods}

\section{Study design and procedures}

The design of the prospective, randomized, double-blind, parallel-group EXIST-3 study has been described previously. ${ }^{9}$ In the core phase, eligible patients were randomized to receive placebo, everolimus LE, or everolimus $\mathrm{HE}$ in addition to a stable regimen of 1-3 AEDs. After the core phase, patients remaining on study were eligible to continue in the extension phase for $\geq 48$ weeks. Maintenance of blinding was preserved during transition to the extension phase by adding the possibility of placebo tablet administration to patients initially randomized to placebo or everolimus LE groups. Investigators were permitted to make their own dose titrations within the targeted trough concentration $\left(\mathrm{C}_{\mathrm{min}}\right)$ range of $3-15 \mathrm{ng} / \mathrm{mL}$ after a transition period to a common target $C_{\min }$ of $6-10 \mathrm{ng} / \mathrm{mL}$ implemented by Interactive Response Technology software to further maintain the blinded nature of the core phase. Rescue medication was allowed in patients with a transient increase in seizure activity but for not more than 14 cumulative days during any 12 week period. Investigators were also permitted to change AEDs or modify the dose of AEDs during the extension phase. Everolimus blood trough levels were measured at weeks 19, 22, 26 , and 30 , and every 12 weeks thereafter to allow dose adjustments to achieve the target $\mathrm{C}_{\text {min }}$ range and also measured 2 weeks after a change in everolimus dose, addition or change in the dose of cytochrome P450 3A4 (CYP3A4)/P-glycoprotein inducer or inhibitor. Patients or caregivers continued to record seizures in seizure diaries throughout the extension phase. Patients continuing to receive clinical benefit at the completion of the extension phase were eligible to continue everolimus in a postextension phase of EXIST-3 (NCT02962414).

\section{End points}

The efficacy end points included change from baseline in SF over time, expressed as RR (percentage of patients with $\geq 50 \%$ reduction in SF) and median PR in SF, determined at 12-week intervals throughout the duration of everolimus treatment. Additional exploratory end points were change from baseline in seizure-free days, exposure-efficacy relationship analysis, safety (frequency of adverse events [AEs] assessed according to the Common Terminology Criteria for AEs, version 4.03), and exposure-safety relationship analysis. Post hoc exploratory efficacy end points assessed the emergence of new responders over time, time to the first 12-week response, and analysis of the persistent responses. Seizure types included in the analysis were described in the report of the core phase of the study. ${ }^{9}$

\section{Statistical analysis}

Evaluable patients included those who received $\geq 1$ dose of everolimus in the core or extension phases of the study and had $\geq 1$ efficacy or safety assessment. Patients were analyzed as a single everolimus-treated group and analyzed separately according to their initial randomization group (patients originally randomized to placebo entering the extension phase with a target everolimus $C_{\min }$ of $3-15 \mathrm{ng} / \mathrm{mL}$, everolimus LE, and everolimus HE groups). The efficacy end points of RR, PR from start of everolimus in SF, and change from start of everolimus in seizure-free days were determined by 12 -week time windows from week 7 after the start of everolimus (from randomization for patients randomized to everolimus and from start of everolimus in the extension phase for patients initially randomized to placebo): from week 7-18, then from week 19-30, and every 12 weeks thereafter. An analysis was performed classifying patients who discontinued everolimus either in the core or extension phases as nonresponders in the time window in which seizures would have been recorded if the patient had not discontinued early. The time to first 12-week response was defined as the time from the start of everolimus until the last day of the first 12-week period when the patient achieved a response (50\% of seizure reduction). A persistent response was defined as a response occurring during any 12 -week interval with no subsequent change to a nonresponder status as of the cutoff date. The change in SF was calculated by 12 week and 2 -week time intervals and by 2 -week time interval for seizure-free days from randomization. Additional details on statistical methodology used to assess the relationship between efficacy, safety, and exposure to everolimus can be found in appendixes e-1 and e-2 (links.lww.com/CPJ/A46). Statistical analysis was performed with SAS (version 9.2). 
Adverse events were similar to those described in previous trials of

everolimus in TSC patients for

nonepileptic disease manifestations.

\section{Standard protocol approvals, registrations, and patient consents}

All patients (or their legal representatives) provided written informed consent before entering the baseline phase. The study was conducted in accordance with the principles of Good Clinical Practice, the Declaration of Helsinki, and all local regulations. The study protocol and all amendments were reviewed and approved by independent ethics committees or institutional review boards for each center. The study is registered with clinicaltrials.gov (NCT01713946).

\section{Classification of evidence}

This interventional study (extension phase) provides Class IV evidence that a sustained effect was observed with everolimus treatment as an adjunctive therapy for the treatment of refractory seizures associated with TSC. Reductions in SF tended to increase over time and were more prominent in patients with greater exposure to the study drug. Adverse events were similar to those described in previous trials of everolimus in TSC patients for nonepileptic disease manifestations.

\section{Data availability}

Novartis supports the publication of scientifically rigorous analysis that is relevant to patient care, regardless of a positive or negative outcome. Qualified external researchers can request access to anonymized patient-level data, respecting patient-informed consent, through clinicalstudydatarequest. com, according to requirements noted on the Web portal.

\section{Results}

Of the 366 patients enrolled (placebo-randomized patients $[\mathrm{n}=119]$, everolimus LE $[\mathrm{n}=117]$, everolimus HE $[\mathrm{n}=$ 130]), 361 received $\geq 1$ dose of everolimus either in the core or extension phases. Five patients randomized to placebo discontinued the study during the core phase, and thus did not enter the extension phase. At the data cutoff date (September 2, 2016), 256 patients continued to receive everolimus; the primary reasons for discontinuation were

Figure 1 Trial profile

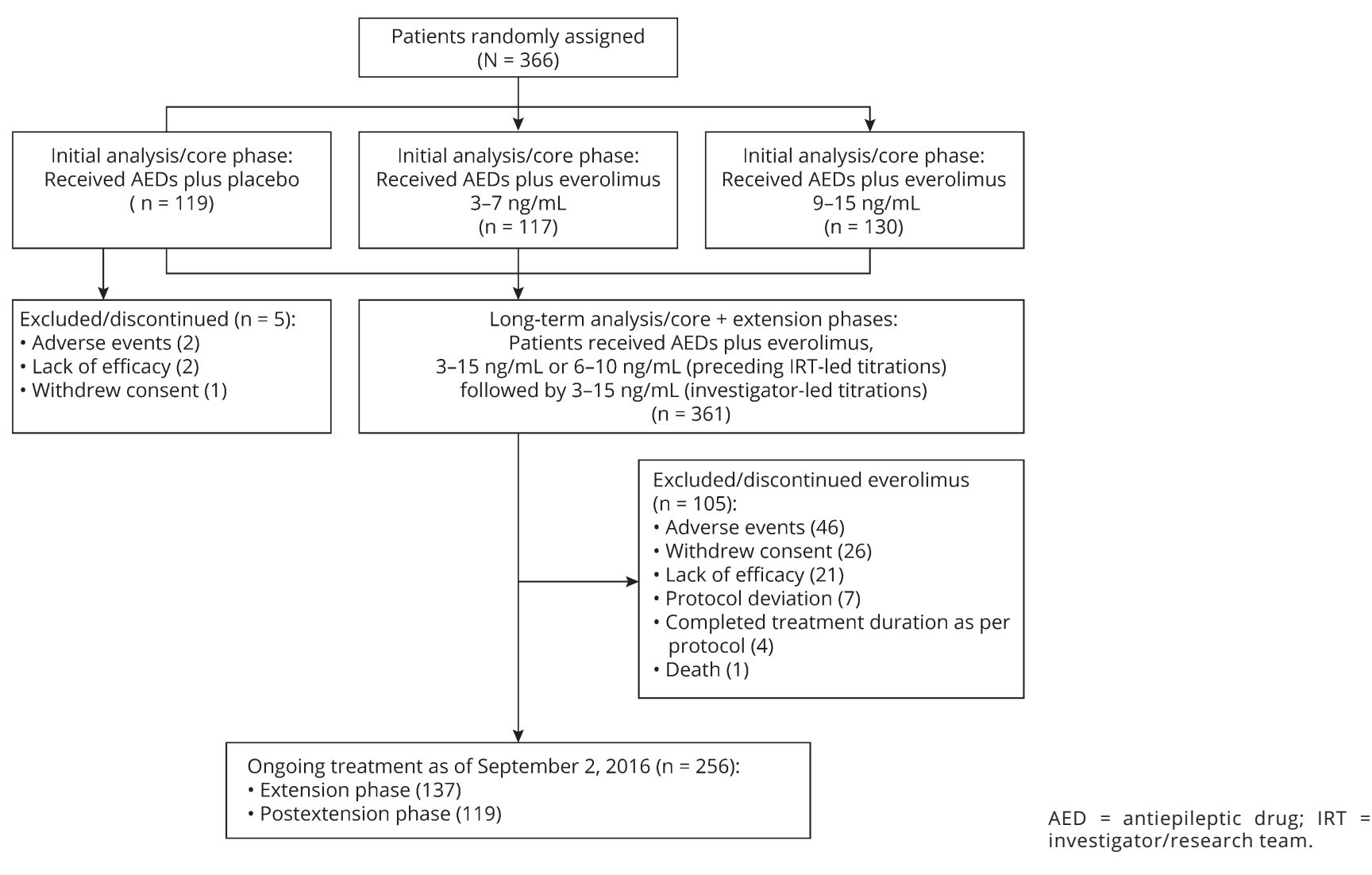


Table 1 Patient demographics, disease characteristics, previous and concomitant AEDs, and rescue medication

\begin{tabular}{|c|c|}
\hline & $\begin{array}{l}\text { All everolimus-treated } \\
\text { patients }(\mathrm{N}=361)\end{array}$ \\
\hline \multicolumn{2}{|l|}{ Age (y) } \\
\hline Median (range) & $10.03(2.2-56.3)$ \\
\hline \multicolumn{2}{|l|}{ Age category (y), n (\%) } \\
\hline$<6$ & $101(28)$ \\
\hline 6 to $<12$ & $109(30.2)$ \\
\hline 12 to $<18$ & $84(23.3)$ \\
\hline 18 to $<65$ & $67(18.6)$ \\
\hline \multicolumn{2}{|l|}{ Sex, n (\%) } \\
\hline Female & $173(47.9)$ \\
\hline Male & $188(52.1)$ \\
\hline \multicolumn{2}{|l|}{ Race, n (\%) } \\
\hline White & $233(64.5)$ \\
\hline Asian & $86(23.8)$ \\
\hline Black & $4(1.1)$ \\
\hline Native American & $1(0.3)$ \\
\hline Pacific islander & $1(0.3)$ \\
\hline Other & $36(10)$ \\
\hline \multicolumn{2}{|l|}{ Body surface area $\left(\mathrm{m}^{2}\right)$} \\
\hline Median (range) & $1.09(0.5-2.6)$ \\
\hline \multicolumn{2}{|l|}{ Mutation status, ${ }^{a}$ n (\%) } \\
\hline TSC1 & $54(17.3)$ \\
\hline TSC2 & $200(63.9)$ \\
\hline Both & $7(2.2)$ \\
\hline No mutation identified & $52(16.6)$ \\
\hline Previous epilepsy surgery, n (\%) & $66(18.3)$ \\
\hline Previous VNS treatment, n (\%) & $43(11.9)$ \\
\hline \multicolumn{2}{|l|}{ AEDs before study start, ${ }^{b} \mathrm{n}(\%)$} \\
\hline 2 & $17(4.7)$ \\
\hline 3 & $37(10.2)$ \\
\hline 4 & $65(18)$ \\
\hline 5 & $68(18.8)$ \\
\hline 6 & $37(10.2)$ \\
\hline$>6$ & $137(38)$ \\
\hline
\end{tabular}

AEDs during the baseline phase, $\mathbf{n}(\%)$
1
$39(10.8)$

Table 1 Patient demographics, disease characteristics, previous and concomitant AEDs, and rescue medication (continued)

\begin{tabular}{ll}
\hline & $\begin{array}{l}\text { All everolimus-treated } \\
\text { patients }(\mathrm{N}=361)\end{array}$ \\
\hline $\mathbf{2}$ & $150(41.6)$ \\
\hline $\mathbf{3}$ & $169(46.8)$ \\
\hline $\mathbf{3}$ & $3(0.8)$
\end{tabular}

Concomitant AEDs at the end of

everolimus treatment, $\mathbf{n}(\%)$

\begin{tabular}{ll}
\hline $\mathbf{0}$ & $4(1.1)$ \\
\hline $\mathbf{1}$ & $41(11.4)$ \\
\hline $\mathbf{2}$ & $143(39.6)$ \\
\hline $\mathbf{2}$ & $173(47.9)$ \\
\hline Any rescue medication, $\mathbf{n}(\%)$ & $103(28.5)$
\end{tabular}

Maximum consecutive days of rescue medication, $\mathbf{n}(\%)$

\begin{tabular}{|c|c|}
\hline $1-2$ & $82(22.7)$ \\
\hline $3-4$ & $12(3.3)$ \\
\hline $5-7$ & $4(1.1)$ \\
\hline$>7$ & $5(1.4)$ \\
\hline $\begin{array}{l}14 \mathrm{~d} \text { of rescue medication in } \\
\text { any } 12 \mathrm{wk}, \mathrm{n}(\%)\end{array}$ & $6(1.7)$ \\
\hline
\end{tabular}

Abbreviations: AED = antiepileptic drug; TSC = tuberous sclerosis complex; VNS = vagal nerve stimulation.

a Mutation status available only for 313 patients. Percentages calculated considering patients with available data.

${ }^{\mathrm{b}}$ Before study start refers to before the screening phase.

AEs (12.7\%), withdrawal of consent (7.2\%), and lack of efficacy (5.8\%; figure 1). Ninety-five patients $(26.3 \%)$ discontinued everolimus before achieving 2 years of follow-up and $103(28.5 \%)$ had $<2$ years of follow-up at the time of this analysis. The median age at the start of everolimus was 10 years $(\mathrm{n}=361)$ with $28 \%$ of patients aged $<6$ years, $81.4 \%$ aged $<18$ years, and $18.6 \%$ aged $\geq 18$ years (table 1 ). The median duration of everolimus exposure was $\sim 21$ months (90.4 weeks; range, 2-165), and the median dose intensity was $6.76 \mathrm{mg} / \mathrm{m}^{2} /$ day (range, 1.1-27.8).

RRs increased over time from the start of everolimus treatment: from 31\% (95\% CI, 26.2-36.1) at week 18 (weeks $7-18, \mathrm{n}=352)$ to $46.6 \%(95 \% \mathrm{CI}, 40.9-52.5)$ at 1 year (weeks 43-54, $\mathrm{n}=298$ ), and to $57.7 \%$ (95\% CI, 49.7-65.4) at 2 years of everolimus exposure (weeks 91-102, $\mathrm{n}=163$; figure $2 \mathrm{~A}$ ). To account for patients' dropout during the study, an analysis considering withdrawn patients as nonresponders was conducted. This analysis showed an RR of $30.2 \%(95 \% \mathrm{CI}, 25.5-35.2)$ at week $18(\mathrm{n}=361), 38.8 \%$ $(95 \%$ CI, 33.7-44.1) at 1 year $(\mathrm{n}=358)$, and $41.0 \%(95 \% \mathrm{CI}$, 

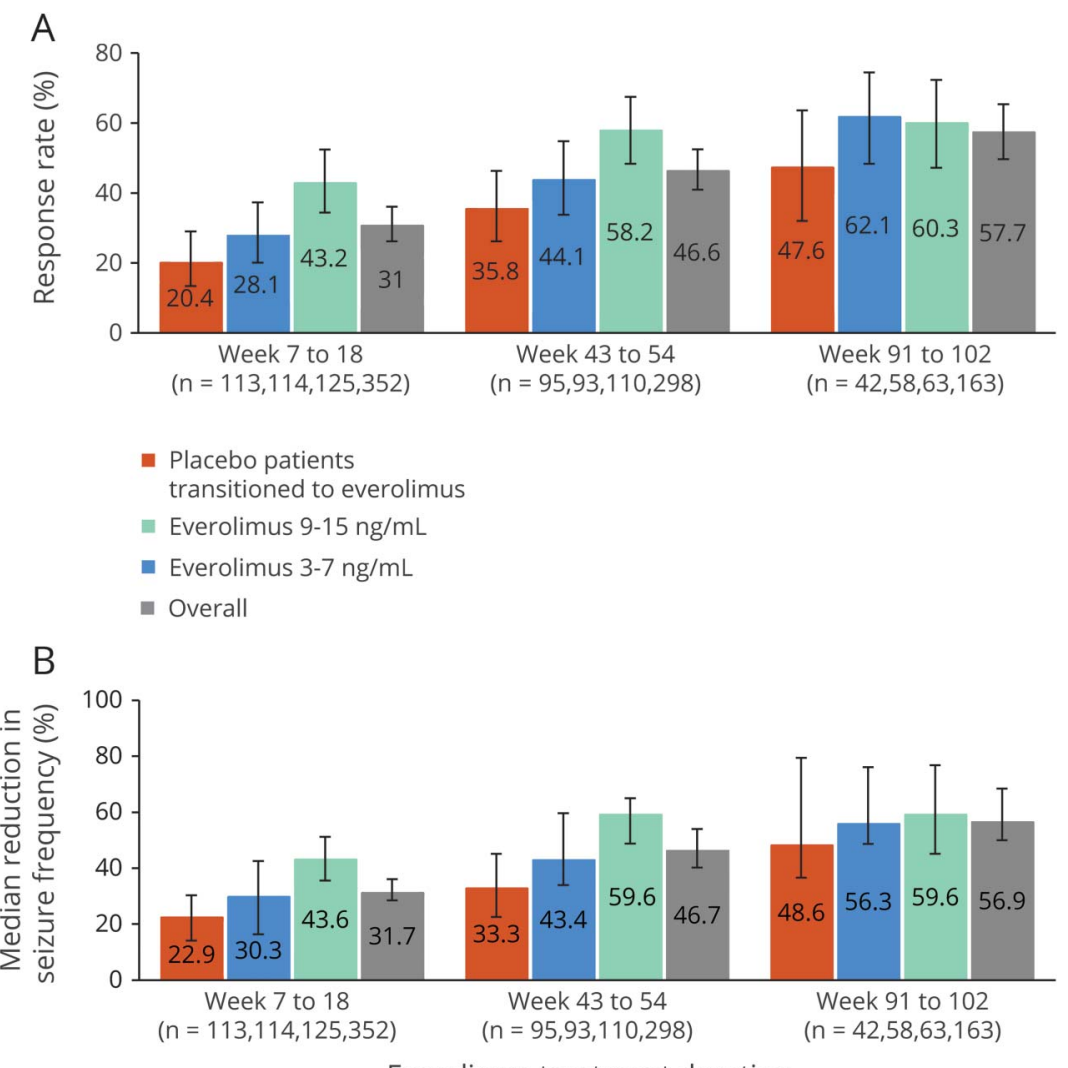

(A) Response rate over time from the start of everolimus. Bars represent $95 \%$ confidence intervals obtained using Clopper-Pearson method. (B) Median percentage reduction in seizure frequency over time from the start of everolimus. Bars represent 95\% confidence intervals based on boot-

Everolimus treatment duration strap percentiles.

$34.6-47.7)$ at 2 years of everolimus exposure $(n=229)$. Efficacy analysis from randomization restricted to evaluable patients at 1 year also demonstrated a sustained reduction in SF (figure e-1, links.lww.com/CPJ/A47). Consistent with the RR, the PR in weekly SF improved over time from $31.7 \%$ (95\% CI, 28.5-36.1) at week 18 to $46.7 \%$ (95\% CI, $40.2-54.0)$ at 1 year, and to $56.9 \%$ (95\% CI, 50-68.4) at 2 years of everolimus exposure (figure $2 \mathrm{~B}$ ). Despite a common target exposure range in the extension phase, the greatest benefit was observed in patients initially randomized to the everolimus HE group, whereas placebo-randomized patients and patients randomized to everolimus LE had a similar pattern of efficacy outcomes over time (figure e-2A). Across all treatment groups, the median weekly SF decreased from

Table 2 Seizure freedom rates over time

\begin{tabular}{llll}
\hline $\begin{array}{l}\text { Seizure freedom } \\
\text { rate over the last 6 mo } \\
\text { before each time point }\end{array}$ & $\begin{array}{l}\text { Month 12 } \\
(\mathrm{N}=275)\end{array}$ & $\begin{array}{l}\text { Month 18 } \\
(\mathrm{N}=201)\end{array}$ & $\begin{array}{l}\text { Month 24 } \\
(\mathrm{N}=117)\end{array}$ \\
\hline $\mathbf{N}(\%)$ & $15(5.45)$ & $20(9.95)$ & $13(11.11)$ \\
\hline $\mathbf{9 5 \%}$ confidence interval & $3.1-8.8$ & $6.2-14.9$ & $6.1-18.3$ \\
\hline
\end{tabular}

95\% confidence intervals obtained using Clopper-Pearson method.
8.6 at the start of everolimus to 3.6 and from 7.1 at the start of everolimus to 2.3 at 1 and 2 years of everolimus exposure, respectively. The median number of additional seizure-free days (per 28-day period) increased from 2.5 days at week 18 to 4.32 days at 1 year and 6.15 days at 2 years of everolimus exposure. The number of patients who were seizure-free over the previous 6 months remained roughly the same at 1 and 2 years although the proportion of patients increased from $5 \%$ $(15 / 275)$ to $11 \%(13 / 117)$, respectively because of the difference in the denominator (table 2). The likelihood of observing a $50 \%$ of reduction in SF (calculated during a 12 week period) 1 year after the start of everolimus was $45 \%$ in patients who transitioned from placebo to everolimus in the extension phase, $55 \%$ in everolimus LE, and $70 \%$ in the everolimus HE group. Fifty percent of patients experienced a persistent response and 59\% of these had persistent responses lasting for $\geq 48$ weeks. Similarly, an increase in the number of seizure-free days was observed in the LE and HE groups; for placebo-randomized patients, the number of seizure-free days was similar to that observed in LE group (figure e-2B). The proportions of patients receiving 1, 2, 3, and $>3$ AEDs at baseline (10.8\%, 41.6\%, 46.8\%, and $0.8 \%)$ were comparable to the proportions of patients receiving the same numbers of concomitant AEDs at week $18(10.8 \%$, $39.5 \%, 47.7 \%$, and $2 \%)$, 1 year $(10.7 \%, 36.7 \%, 48.3 \%$, and $4 \%)$, and 2 years $(6.7 \%, 39.3 \%, 46.6 \%$, and $4.9 \%)$, 
respectively of everolimus exposure. Forty-seven percent of patients received the same AED regimen for $\geq 54$ weeks after the start of everolimus. Exposure-efficacy analysis suggested that reductions in SF were both time and exposure dependent. Higher everolimus exposure, lower baseline SF, and longer treatment duration were associated with a lower postbaseline SF. However, the effect of longer treatment duration on further increases in efficacy seems to be modest (appendix e-1, links.lww.com/CPJ/A46).

The most frequent all-grade AEs due to any cause, reported in $>20 \%$ of patients throughout the study included stomatitis (35.2\%), pyrexia (34.6\%), diarrhea (28.5\%), mouth ulceration (27.7\%), nasopharyngitis $(23.8 \%)$, and upper respiratory tract infection (22.4\%). Grade 3 or 4 AEs were reported in $40.2 \%$ of patients, the most frequent were pneumonia (6.9\%), status epilepticus (3.3\%), seizures (2.8\%), and stomatitis (2.5\%; table 3). Overall, $5.3 \%$ of patients experienced grade 4 AEs; the most common were status epilepticus, pneumonia (3 patients each), and neutropenia ( 2 patients). The incidence of new or changed grade 3 or 4 AEs during the second year (period between 12 and 24 months) of everolimus seemed to be similar to that observed within the first 6 months of treatment ( $\leq 6$ months, $21.6 \%$; >6-12 months, $13.8 \%$; second year, $19.9 \%$; third year, $4.7 \%)$. However, at the data cutoff date, fewer than $40 \%$ of patients completed a 2-year exposure to everolimus, preventing a definitive interpretation of these results. The most frequent

Table 3 Adverse events of any cause reported in $\geq 10 \%$ of patients $(\mathrm{N}=361)$

\begin{tabular}{lll}
\hline Adverse events $^{\text {a }}$ & $\begin{array}{l}\text { All grades, } \\
\mathrm{n}(\%)\end{array}$ & $\begin{array}{l}\text { Grade 3 or 4, } \\
\mathrm{n}(\%)\end{array}$ \\
\hline Stomatitis $^{\mathbf{b}}$ & $246(68.1)$ & $17(4.7)$ \\
\hline Pyrexia $^{\circ}$ & $125(34.6)$ & $6(1.7)$ \\
\hline Diarrhea & $103(28.5)$ & $4(1.1)$ \\
\hline Nasopharyngitis & $86(23.8)$ & $1(0.3)$ \\
\hline Upper respiratory tract infection & $81(22.4)$ & $1(0.3)$ \\
\hline Vomiting & $72(19.9)$ & $3(0.8)$ \\
\hline Cough & $69(19.1)$ & 0 \\
\hline Hypercholesterolemia & $49(13.6)$ & $1(0.3)$ \\
\hline Headache & $46(12.7)$ & $1(0.3)$ \\
\hline Rash & $42(11.6)$ & 0 \\
\hline Pneumonia & $39(10.8)$ & $25(6.9)$ \\
\hline Pharyngitis & $37(10.2)$ & $3(0.8)$ \\
\hline Bronchitis & $36(10)$ & $4(1.1)$ \\
\hline Gastroenteritis & $36(10)$ & $8(2.2)$ \\
\hline
\end{tabular}

a Only includes adverse events occurring on or after the start of everolimus and no more than 30 days after the discontinuation of everolimus.

${ }^{b}$ Included all the related terms-mouth ulceration, aphthous ulcer, lip ulceration, tongue ulceration, mucosal inflammation, and gingival pain. treatment-related AEs reported were stomatitis (33.5\%), mouth ulceration $(26.0 \%)$, diarrhea $(10.5 \%)$, aphthous ulcer (10.2\%), and pyrexia (10.2\%). Serious AEs were reported in $33.2 \%$ of patients, and the most frequent were pneumonia (9.1\%), seizure $(4.2 \%)$, and status epilepticus (3.6\%). In addition, there was no apparent increase in the emergence of allgrade treatment-related AEs over time ( $\leq 6$ months, $77.8 \%$; $>6-12$ months, $46.2 \%$; second year, $45.5 \%)$. Adverse events led to treatment discontinuation in 47 patients (13\%), primarily because of pneumonia (1.7\%) and stomatitis (1.4\%). The most common AEs necessitating dose adjustments or interruption were stomatitis (9.4\%), mouth ulceration (9.1\%), pyrexia (6.1\%), and pneumonia (5.3\%). Menstrual irregularities were reported in 12 patients (3.3\%). Exposure-safety relationship analysis outcomes are provided in appendix e-2, links.lww. com/CPJ/A46. The exposure to everolimus, expressed as timenormalized (TN) $\mathrm{C}_{\min }$ up to the first grade $3 / 4$ event or up to the last dose of everolimus, was similar between patients who reported grade $3 / 4 \mathrm{AEs}$ and patients who did not report grade 3/4 AEs. There were 4 patients with $\mathrm{TN} \mathrm{C}_{\min }>15 \mathrm{ng} / \mathrm{mL}: 3$ reported grade 3 and 4 events, but none reported unexpected toxicities or safety concerns (table 4). Two deaths occurred during the extension phase-both in pediatric patientsbecause of pneumonia (suspected to be treatment related) and sudden unexpected death in epilepsy (SUDEP, not suspected to be treatment related). Two additional deaths occurred after the data cutoff date, 1 in a child because of septic shock (suspected to be treatment related) and other in an adult patient because of SUDEP (not suspected to be treatment related).

\section{Discussion}

In this prospective phase 3 trial, treatment with everolimus as an adjunctive therapy for nearly 2 years produced clinically relevant and sustained reductions in SF over time in patients with treatment-refractory seizures associated with TSC. During the core phase, RRs achieved with everolimus LE and HE were $28.2 \%$ and $40 \%$, and the median PR were $29.3 \%$ and $39.6 \%$, respectively. ${ }^{9}$ A substantial benefit was demonstrated with continuous use of everolimus. The treatment effect was sustained over time (RR and median PR at week 18, 1 year, and 2 years of everolimus exposure were $31 \%, 46.6 \%, 57.7 \%$, and $31.7 \%, 46.7 \%, 56.9 \%$, respectively). However, the number of evaluable patients reduced over time. Our study results are consistent with the long-term efficacy data reported in an open-label trial of everolimus for intractable epilepsy for up to 4 years wherein the seizure RRs increased over time $(76 \%, 75 \%, 80 \%$, and $93 \%$ of RR at $12,24,36$, and 48 months, respectively). ${ }^{10}$ However, the study had a modest sample size (20 patients). EXIST-3 is the first phase 3 placebo-controlled epilepsy trial in a large population of patients with TSC $(\mathrm{N}=366)$, including high-risk patients. EXIST-3 results are consistent with another open-label trial (15 patients), which demonstrated efficacy of everolimus in patients with TSC and epilepsy. ${ }^{11}$ In EXIST-3, new responders emerged with a longer everolimus treatment duration and $50 \%$ of patients experienced persistent responses. 
Table 4 First occurrence of grade $3 / 4$ adverse events by treatment phase and by time-normalized $C_{\min }$

\begin{tabular}{|c|c|c|c|c|}
\hline \multirow[b]{3}{*}{$\begin{array}{l}\text { Time-normalized } \\
C_{\min }, n g / m L\end{array}$} & \multicolumn{4}{|l|}{ Core phase } \\
\hline & \multicolumn{2}{|l|}{ Titration period } & \multicolumn{2}{|l|}{ Maintenance period } \\
\hline & $\begin{array}{l}\text { Patients with at least } 1 \text { grade } \\
3 / 4 \text { AE while on everolimus } \\
(N=27), n(\%)\end{array}$ & $\begin{array}{l}\text { Patients without any grade } \\
3 / 4 \text { AE while on everolimus } \\
(\mathrm{N}=218), \mathrm{n}(\%)\end{array}$ & $\begin{array}{l}\text { Patients with at least } 1 \text { grade } \\
3 / 4 \mathrm{AE} \text { while on everolimus } \\
(\mathrm{N}=18), \mathrm{n}(\%)\end{array}$ & $\begin{array}{l}\text { Patients without any grade } \\
3 / 4 \mathrm{AE} \text { while on everolimus } \\
(\mathrm{N}=196), \mathrm{n}(\%)\end{array}$ \\
\hline$<3$ & $5(18.5)$ & $11(5.0)$ & 0 & $9(4.6)$ \\
\hline $3-7$ & $15(55.6)$ & 161 (73.9) & $11(61.1)$ & $123(62.8)$ \\
\hline$>7$ to $<9$ & $2(7.4)$ & $23(10.6)$ & $3(16.7)$ & 39 (19.9) \\
\hline $9-15$ & $2(7.4)$ & $22(10.1)$ & $4(22.2)$ & $25(12.8)$ \\
\hline \multirow[t]{3}{*}{$>15$} & $3(11.1)$ & $1(0.5)$ & 0 & 0 \\
\hline & \multicolumn{4}{|l|}{ Extension phase } \\
\hline & \multicolumn{2}{|l|}{ Transition phase } & \multicolumn{2}{|l|}{ Follow-up } \\
\hline $\begin{array}{l}\text { Time-normalized } \\
\mathrm{C}_{\min }, \mathrm{ng} / \mathrm{mL}\end{array}$ & $\begin{array}{l}\text { Patients with at least } 1 \text { grade } \\
3 / 4 \mathrm{AE} \text { while on everolimus } \\
(\mathrm{N}=18), \mathrm{n}(\%)\end{array}$ & $\begin{array}{l}\text { Patients without any grade } \\
3 / 4 \mathrm{AE} \text { while on everolimus } \\
(\mathrm{N}=284), \mathrm{n}(\%)\end{array}$ & $\begin{array}{l}\text { Patients with at least } 1 \text { grade } \\
3 / 4 \mathrm{AE} \text { while on everolimus } \\
(\mathrm{N}=73), \mathrm{n}(\%)\end{array}$ & $\begin{array}{l}\text { Patients without any grade } \\
3 / 4 \mathrm{AE} \text { while on everolimus } \\
(\mathrm{N}=204), \mathrm{n}(\%)\end{array}$ \\
\hline$<3$ & $1(5.6)$ & $16(5.6)$ & $1(1.4)$ & $7(3.4)$ \\
\hline 3-7 & $12(66.7)$ & 170 (59.9) & 35 (47.9) & $120(58.8)$ \\
\hline$>7$ to $<9$ & $3(16.7)$ & $61(21.5)$ & $23(31.5)$ & $43(21.1)$ \\
\hline $9-15$ & $2(11.1)$ & $37(13.0)$ & $14(19.2)$ & $34(16.7)$ \\
\hline$>15$ & 0 & 0 & 0 & 0 \\
\hline
\end{tabular}

Abbreviation: $\mathrm{AE}=$ adverse event.

Although a large number of patients $(n=202)$ had achieved 2 years of treatment follow-up, there was a decreasing number of evaluable patients over time. Ninety-five patients discontinued everolimus before achieving 2 years of followup, and 103 patients did not attain the 2 years of follow-up at the time of data cutoff. Some degree of dropout is expected in patients with refractory epilepsy during long-term therapy as evidenced by earlier large multicenter trials of AEDs. ${ }^{12}$ Nevertheless, a conservative analysis, which considered patients who discontinued treatment as nonresponders, confirmed the sustained efficacy of everolimus over time and suggested that once patients have responded, the efficacy of everolimus is typically maintained. In addition, the median weekly SF decreased during 2 years of treatment and the number of patients who were seizure-free over the previous 6 months remained roughly the same at 1 and 2 years while the proportion of patients increased from 5\% after 1 year to $11 \%$ after 2 years.

In this study, prompt and robust reductions in SF were observed soon after transitioning to everolimus in the extension phase from placebo, suggesting additional SF reduction achieved beyond the placebo effect observed in the core phase. Despite the goal of achieving a common target exposure range of 3-15 $\mathrm{ng} / \mathrm{mL}$, the pattern of reduction in $\mathrm{SF}$ in placebo-randomized patients was similar to that of the everolimus LE group. The HE group achieved the greatest reduction, possibly due to higher $\mathrm{C}_{\text {min }}$ levels attained by this group. The low frequency of days without seizures observed during the study had a minimal effect on data interpretation. Fewer everolimus-treated patients required rescue medications; $50 \%$ of patients received $>2$ concomitant AEDs from beginning to end of everolimus treatment with $47 \%$ receiving the same AED regimen for $\geq 1$ year. This suggests that efficacy is maintained over a longer period with a reduced need for rescue medications or changes to concomitant AED treatment.

The long-term safety profile of everolimus was consistent with that previously reported in the core phase of this study ${ }^{9}$ and in other studies of everolimus in TSC-associated clinical settings. ${ }^{13,14}$ Few clinical trials have assessed the role of mTOR inhibitors for seizures in TSC. This study confirms that AEs observed with prolonged use of everolimus are consistent with established risks, do not overlap with the typical side effects of conventional AEDs, and no new safety issues were found to manifest over time. Stomatitis and mouth ulceration, the primary identified risks associated with everolimus treatment, continued to be the most frequently reported AEs and were the primary cause of dose interruptions or reductions. The incidence of treatment-related AEs by period of emergence did not increase over time with 
The lack of a placebo arm in the extension phase of the study and the lack of assessments related to change in AEDs are limitations.

longer exposure to everolimus. However, these results should be interpreted with caution because less than $40 \%$ of patients were exposed to everolimus for a period of $\geq 2$ years, whereas approximately $80 \%$ of patients were exposed to everolimus for a period of $\geq 1$ year. With extended treatment, an increased incidence and severity of infections (primarily pneumonia) were observed in younger children ( $<6$ years), which is consistent with the known pattern of pneumonia reported in the general population. Pneumonia is a major cause of morbidity and mortality worldwide in children younger than 5 years in general, ${ }^{15,16}$ whereas renal disease and SUDEP are considered significant causes of mortality in TSC. $^{17}$ Two deaths occurred because of pneumonia and septic shock, suspected to be treatment related.

The lack of a placebo arm in the extension phase of the study and the lack of assessments related to change in AEDs are limitations. In addition, these data should be interpreted with caution taking into account patient withdrawals and patients still receiving treatment in the extension phase, resulting in fewer evaluable patients over time for the extension phase of the study. In conclusion, our findings suggest that long-term exposure to everolimus as adjunctive therapy provides a sustained reduction in SF that tends to increase over time. Adverse events were similar to those of previous placebo-controlled trials of everolimus in TSC, with a favorable benefit-risk ratio that improves with ongoing treatment. These results suggest that long-term treatment of TSC-associated refractory seizures with everolimus has a favorable risk-benefit ratio.

\section{Author contributions}

D.N. Franz: study design, data collection, data analysis, data interpretation, drafting and revising the manuscript. J.A. Lawson: study design, data collection, data interpretation, drafting and revising the manuscript. Z. Yapici and H. Ikeda: data collection, drafting and revising the manuscript. T. Polster: data collection, data interpretation, drafting and revising the manuscript. R. Nabbout: data analysis, data interpretation, drafting and revising the manuscript. P. Curatolo: study design, data analysis, data interpretation, drafting and revising the manuscript. P.J. de Vries: study design, data interpretation, drafting and revising the manuscript. D.J. Dlugos: study design, data collection, data analysis, data interpretation, drafting and revising the manuscript. M. Voi: data collection, data analysis, data interpretation, drafting and revising the manuscript. J. Fan: data analysis, data interpretation, drafting and revising the manuscript. A. Vaury: statistical data analysis, data interpretation, drafting and revising the manuscript. D. Pelov: study design, data collection, data interpretation, drafting and revising the manuscript. J.A. French: study design, data analysis, data interpretation, drafting and revising the manuscript.

\section{Acknowledgment}

The authors thank the patients and their families, the study investigators, and the study site personnel for their participations and contributions to this study. The authors thank Anne-Laure Louveau and Severine Peyrard for their contributions with the statistical analysis of the data. Medical writing and editorial assistance limited to copy editing, formatting and administrative support, but not development of intellectual content, was provided by Rama Mylapuram, PharmD, Novartis Healthcare Pvt. Ltd.

\section{Study funding}

This study was funded by Novartis Pharmaceuticals Corporation.

\section{Disclosure}

D.N. Franz has received funding for travel and speaker honoraria from Novartis; has served as a consultant to Novartis for trial design (funds paid to institution); serves on a speakers' bureau for Novartis; has received research funding to his institution for clinical trials from Novartis; and has participated in medico-legal cases. J.A. Lawson has served on a scientific advisory board for and received research support from Novartis. Z. Yapici and H. Ikeda report no disclosures. T. Polster serves on scientific advisory boards for Zogenix, Desitin, and Novartis; and has received speaker honoraria from Zogenix, Shire, Desitin, UCB, and Novartis. R. Nabbout serves on scientific advisory boards for Novartis and Zogenix; has received funding for travel from Shire and speaker honoraria from Novartis, Cyberonics, Eisai, and Advicennes; serves on the editorial advisory board of Epilepsia Open; and receives research support from Shire, Zogenix, GW Pharma, Eisai, and EU (FP7). P. Curatolo has served on a scientific advisory board for Eisai, Shire, and Novartis; has received funding for travel and/or speaker honoraria from Novartis and Shire; and serves on editorial boards for Journal Child Neurology, Brain and Development, and Pediatric Neurology. P.J. de Vries serves on a scientific advisory board and as a consultant for Novartis; has received funding for travel to meetings from Novartis; serves on editorial boards for Journal of Intellectual Disability Research and Autism Research and as an Associate Editor for Journal of Child of Adolescent Mental Health; and has received research support from Novartis, South African National Department of Social Development, Struengmann Foundation, and National Research Foundation of South Africa. D.J. Dlugos serves on a DSMB for a study sponsored by SAGE Pharmaceuticals; and receives research support from Insys Therapeutics, Bio-Pharm Solutions, NIH/NINDS, Commonwealth of Pennsylvania Department of Health, and The Epilepsy Study Consortium. M. Voi is an employee of Novartis and his spouse receives research support from Johnson \& Johnson. J. Fan is an employee of Novartis and 
receives stocks as part of compensation. A. Vaury is an employee of Novartis. D. Pelov is an employee of Novartis and receives stocks as part of compensation. J.A. French serves on a scientific advisory board or consultant for the Epilepsy Foundation, Acadia, Acorda, Adamas, Alexza, Anavex, Axcella Health, Biogen, BioPharm Solutions, Cavion, Cerecor, Cerebral Therapeutics, Concert Pharmaceuticals, Covance, CuroNZ, Eisai, Empatica, Engage, Georgia Regents University, GlaxoSmithKline, GW Pharma, J\&J Pharmaceuticals, Marinus, MonosolRx, Monteris, NestleHealth Science, Neurelis, Novartis, Otsuka, Ovid, Pfizer, Pfizer-Neusentis, Sage Therapeutics, Shire, SK Life Sciences, Sunovion, Takeda, UCB, Inc., Upsher Smith, Ultragenyx, Xenon Pharmaceuticals, Xeris, Zogenix and Zynerba; has received paid travel to present findings at scientific meetings, present at investigators' meetings, attend advisory boards, or give lectures from Epilepsy Study Consortium, Epilepsy Foundation, International League Against Epilepsy, American Academy of Neurology, American Epilepsy Foundation, Adamas, Biogen, Eisai, Engage, GW Pharma, GSK, Novartis, Otsuka, Ovid, Pfizer, Sage, Sunovion, Takeda, UCB, Ultragenyx, Upsher-Smith, Zynerba, Blackfynn Pfizer, PfizerNeusentis, Sage, SK Life Sciences, Sunovion, Takeda, UCB, Inc., Upsher Smith, Zogenix, and Zynerba; serves on editorial boards for Lancet Neurology, Neurology Today, and Epilepsy Currents; serves as President of Epilepsy Study Consortium, which receives money from multiple pharmaceutical companies; consults for a number of companies on behalf of the Epilepsy Study Consortium, which pays a fixed $30 \%$ of her NYU salary, some of which may come from consulting fees. Companies involved include Acadia, Acorda, Adamas, Alexza, Anavex, Axcella Health, Biogen, BioPharm Solutions, Cavion, Cerecor, Cerebral Therapeutics, Concert Pharmaceuticals, Covance, CuroNZ, Eisai, Empatica, Engage, Georgia Regents University, Glaxo Smith-Kline, GW Pharma, J\&J Pharmaceuticals, Marinus, MonosolRx, Monteris, Nestle-Health Science, Neurelis, Novartis, Otsuka, Ovid, Pfizer, Pfizer-Neusentis, Sage Therapeutics, Shire, SK Life Sciences, Sunovion, Takeda, UCB, Inc., Upsher Smith, Ultragenyx, Xenon Pharmaceuticals, Xeris, Zogenix and Zynerba; has received research support from Alexza, Acorda,
LCGH, Eisai Medical Research, Lundbeck, Neurelis, Pfizer, SK Life Sciences, Sunovion, Takeda, UCB, Upsher-Smith, Biogen, NIH/NINDS, Epilepsy Research Foundation, Epilepsy Therapy Project, and Epilepsy Study Consortium; and is Chief Scientific Officer for the Epilepsy Foundation for which NYU receives salary support. Full disclosure form information provided by the authors is available with the full text of this article at Neurology.org/cp.

Received December 27, 2017. Accepted in final form May 14, 2018.

\section{References}

1. Krueger DA, Wilfong AA, Holland-Bouley K, et al. Everolimus treatment of refractory epilepsy in tuberous sclerosis complex. Ann Neurol 2013;74:679-687.

2. Curatolo P, Moavero R, de Vries PJ. Neurological and neuropsychiatric aspects of tuberous sclerosis complex. Lancet Neurol 2015;14:733-745.

3. Chu-Shore CJ, Major P, Camposano S, Muzykewicz D, Thiele EA. The natural history of epilepsy in tuberous sclerosis complex. Epilepsia 2010;51:1236-1241.

4. Citraro R, Leo A, Constanti A, Russo E, De Sarro G. mTOR pathway inhibition as a new therapeutic strategy in epilepsy and epileptogenesis. Pharmacol Res 2016;107:333-343.

5. Cardamone M, Flanagan D, Mowat D, Kennedy SE, Chopra M, Lawson JA. Mam malian target of rapamycin inhibitors for intractable epilepsy and subependymal giant cell astrocytomas in tuberous sclerosis complex. J Pediatr 2014;164:1195-1200.

6. Meikle L, Pollizzi K, Egnor A, et al. Response of a neuronal model of tuberous sclerosis to mammalian target of rapamycin (mTOR) inhibitors: effects on mTORC and Akt signaling lead to improved survival and function. J Neurosci 2008;28 5422-5432.

7. Sadowski K, Kotulska-Jozwiak K, Jozwiak S. Role of mTOR inhibitors in epilepsy treatment. Pharmacol Rep 2015;67:636-646.

8. Zeng LH, Xu L, Gutmann DH, Wong M. Rapamycin prevents epilepsy in a mouse model of tuberous sclerosis complex. Ann Neurol 2008;63:444-453.

9. French JA, Lawson JA, Yapici Z, et al. Adjunctive everolimus therapy for treatmentresistant focal-onset seizures associated with tuberous sclerosis (EXIST-3): a phase 3 , randomised, double-blind, placebo-controlled study. Lancet 2016;388:2153-2163.

10. Krueger DA, Wilfong AA, Mays M, et al. Long-term treatment of epilepsy with everolimus in tuberous sclerosis. Neurology 2016;87:2408-2415.

11. Samueli S, Abraham K, Dressler A, et al. Efficacy and safety of Everolimus in children with TSC: associated epilepsy: pilot data from an open single-center prospective study. Orphanet J Rare Dis 2016;11:145.

12. French JA, Kanner AM, Bautista J, et al. Efficacy and tolerability of the new antiepileptic drugs, II: treatment of refractory epilepsy: report of the TTA and QSS Subcommittees of the American Academy of Neurology and the American Epilepsy Society. Epilepsia 2004;45:410-423.

13. Bissler JJ, Kingswood JC, Radzikowska E, et al. Everolimus for renal angiomyolipoma in patients with tuberous sclerosis complex or sporadic lymphangioleiomyomatosis: extension of a randomized controlled trial. Nephrol Dial Transpl 2016;31:111-119.

14. Franz DN, Belousova E, Sparagana S, et al. Long-term use of everolimus in patients with tuberous sclerosis complex: final results from the EXIST-1 study. PLoS One 2016;11:e0158476.

15. Pneumonia. WHO Fact sheet. 2017. Available at who.int/mediacentre/factsheets/ fs331/en/. Accessed October 11, 2017.

16. Scott JA, Brooks WA, Peiris JS, Holtzman D, Mulholland EK. Pneumonia research to reduce childhood mortality in the developing world. J Clin Invest 2008;118: 1291-1300.

17. Amin S, Lux A, Calder N, Laugharne M, Osborne J, O'Callaghan F. Causes of mortality in individuals with tuberous sclerosis complex. Dev Med Child Neurol 2017; 59:612-617.

\section{Subspecialty Alerts by E-mail!}

Customize your online journal experience by signing up for e-mail alerts related to your subspecialty or area of interest. Access this free service by clicking on the "My Alerts" link on the home page. An extensive list of subspecialties, methods, and study design choices will be available for you to choose from-allowing you priority alerts to cutting-edge research in your field! 


\section{Neurology ${ }^{\circ}$ Clinical Practice}

Everolimus for treatment-refractory seizures in TSC: Extension of a randomized
controlled trial

David N. Franz, John A. Lawson, Zuhal Yapici, et al.

Neurol Clin Pract 2018;8;412-420 Published Online before print September 26, 2018

DOI 10.1212/CPJ.0000000000000514

This information is current as of September 26, 2018

Updated Information \&

Services

References

Citations

Subspecialty Collections

Permissions \& Licensing

Reprints including high resolution figures, can be found at:

http://cp.neurology.org/content/8/5/412.full.html

This article cites 16 articles, 1 of which you can access for free at: http://cp.neurology.org/content/8/5/412.full.html\#\#ref-list-1

This article has been cited by 1 HighWire-hosted articles: http://cp.neurology.org/content/8/5/412.full.html\#\#otherarticles

This article, along with others on similar topics, appears in the following collection(s):

All Epilepsy/Seizures

http://cp.neurology.org//cgi/collection/all_epilepsy_seizures

Class IV

http://cp.neurology.org//cgi/collection/class_iv

Information about reproducing this article in parts (figures,tables) or in its entirety can be found online at:

http://cp.neurology.org/misc/about.xhtml\#permissions

Information about ordering reprints can be found online:

http://cp.neurology.org/misc/addir.xhtml\#reprintsus

Neurol Clin Pract is an official journal of the American Academy of Neurology. Published continuously since 2011, it is now a bimonthly with 6 issues per year. Copyright Copyright @ 2018 The Author(s). Published by Wolters Kluwer Health, Inc. on behalf of the American Academy of Neurology.. All rights reserved. Print ISSN: 2163-0402. Online ISSN: 2163-0933.

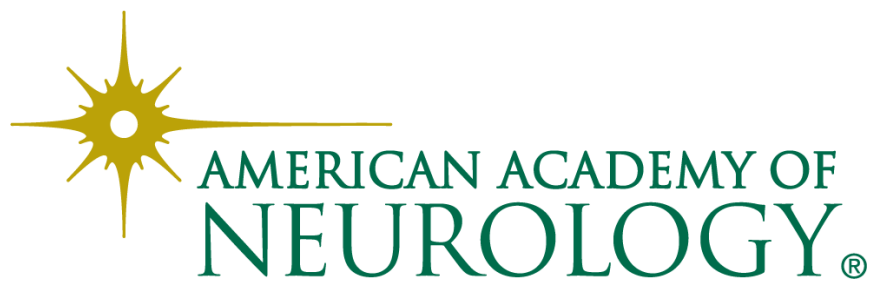

